\title{
Effects of Oxcarbazepine Use on Hemogram, Liver, Thyroid Functions, Lipid Profile in Childhood Epilepsies
}

\author{
๑illknur Girişgen ${ }^{1}$, ๑ Sermet Yıldırmışs ${ }^{2}, \oplus$ Asım Örem ${ }^{3}$, ๑ Fatma Müjgan Sönmez ${ }^{4}$ \\ ${ }^{1}$ Department of Pediatric Nephrology, Pamukkale University Faculty of Medicine, Denizli, Turkey \\ ${ }^{2}$ Department of Biochemical, Karadeniz Technical University Pharmacy Faculty, Trabzon, Turkey \\ ${ }^{3}$ Department of Biochemical, Karadeniz Technical University Faculty of Medicine, Trabzon, Turkey \\ ${ }^{4}$ Department of Pediatric Neurology, Guven Hospital, Ankara, Turkey
}

\begin{abstract}
Introduction: This study aims to investigate the effects of oxcarbazepine on hematological parameters, renal, liver, thyroid functions, plasma electrolyte, lipid, lipoprotein (a), vitamin B12 and folic acid levels.

Methods: Fifteen idiopathic partial epilepsy patients were included in this study. Three patients were excluded from this study because of irregular drug use $(n=1)$ and the requirement of additional antiepileptic treatment due to resistant epilepsy $(n=2)$. Blood samples were taken in the morning following a 12-hour fasting period. Serum samples were examined as for hematological parameters, sodium ( $\mathrm{Na}$ ), potassium (K), calcium (Ca), phosphorus (P), glucose, blood urea nitrogen (BUN), alkaline phosphatase (ALP), alanine aminotransferase (ALT), aspartate aminotransferase (AST), gamma-glutamyl transferase (GGT), total cholesterol, triglyceride, low density lipoprotein-cholesterol (LDL-K), high density lipoprotein-cholesterol (HDL-K), apolipoprotein $A(A p o-A)$, apolipoprotein B (Apo) -B), lipoprotein a ( $L p$ a), free and total triiodothyronine (T3), tetraiodotyrosine (T4), thyroid-stimulating hormone (TSH), folic acid and vitamin B12 levels at the beginning of treatment, at the $3^{\text {rd }}$, $6^{\text {th }}$ and $12^{\text {th }}$ months.

Results: Significant changes were not detected in hematologic parameters, Na, K, Ca, P, glucose, BUN, AST, ALT, ALP, total cholesterol, triglyceride, LDL-C, HDL-C, Apo-A, Lp (a), fT3, TSH, folic acid and vitamin B12 levels at the $3^{\text {rd }}, 6^{\text {th }}$, and $12^{\text {th }}$ months of treatment. A statistically insignificant increase in GGT and a statistically insignificant decrease in fT4 levels were detected at the $3^{\text {rd }}, 6^{\text {th }}, 12^{\text {th }}$ months. A significant increase was detected in Apo-B levels at the third month of treatment, which returned to normal limits at the $12^{\text {th }}$ months. There was a statistically significant increase in Lp (a) levels at the $12^{\text {th }}$ month compared to baseline and the $6^{\text {th }}$-month values $(p<0.05)$.

Discussion and Conclusion: We suggest that liver enzymes, thyroid function tests and Lp (a) levels, which are risk factors for atherosclerosis, should be monitored in children using oxcarbazepine.

Keywords: Child; epilepsy; lipoprotein (a); oxcarbazepine.
\end{abstract}

$E^{p}$ pilepsy is a chronic disease that affects $1-3 \%$ of the population, and arises from the increased excitability of neurons in the brain, requiring stereotypic and long-term use of drugs related to consciousness, behavior, emotion, locomotor or perception functions for a limited period of time in the clinic ${ }^{[1]}$. Antiepileptics have negative effects on the nervous, hematopoietic, skeletal, hepatic and endocrine systems due to their chronic use ${ }^{[2]}$.

Correspondence (Iletişim): Ilknur Girişgen, M.D. Pamukkale Universitesi Tip Fakultesi Cocuk Sagligi ve Hastaliklari Anabilim Dali, Cocuk Nefroloji Bilim Dali, Denizli, Turkey

Phone (Telefon): +90 5058439145 E-mail (E-posta): igirisgen78@hotmail.com

Submitted Date (Başvuru Tarihi): 23.10.2019 Accepted Date (Kabul Tarihi): 28.10.2019

Copyright 2019 Haydarpaşa Numune Medical Journal

OPEN ACCESS This is an open access article under the CC BY-NC license (http://creativecommons.org/licenses/by-nc/4.0/). 
Since the year 2000, oxcarbazepine, which is a 10-keto analogue of carbamazepine, have been used in monotherapy or polytherapy in simple partial, complex partial and generalized seizures in children and adults ${ }^{[3]}$. Similar to carbamazepine, it exerts an antiepileptic effect by blocking sodium and calcium channels, as well. Its most important difference from carbamazepine is that it is minimally metabolized by cytochrome $P 450$ enzyme system in the liver with lower affinity to proteins, and its metabolite is glucuronidated before it is excreted in the urine. Thus, the interaction with other drugs metabolized in the liver is at a minimal level and exerts lower effects on liver enzymes and lipids ${ }^{[3,4]}$.

Although many studies in the literature are available on the efficacy and safety of oxcarbazepine, some studies have contradicted these results ${ }^{[5]}$. The most common side effects of oxcarbazepine include side effects involving the side effects involving the rash-like eruptions, central nervous system such as headache, dizziness, gastrointestinal side effects, such as vomiting, nausea, diarrhea, and hyponatremia ${ }^{[6]}$.

The present study aims to investigate the effects of oxcarbazepine on hemogram, liver, thyroid function tests, lipid profile, Lp (a), vitamin B12 and folate.

\section{Materials and Methods}

Fifteen patients presented to our pediatric neurology outpatient clinic between 2002 and 2004, who had been started on oxcarbazepine treatment with the diagnosis of epilepsy were included in this study. Epilepsy types were determined using the ILAE 1989 classification based on characteristic findings of seizures and electroencephalograms (EEG) ${ }^{[7]}$. Oxcarbazepine treatment was started at $15 \mathrm{mg} / \mathrm{kg} /$ day and gradually increased to $30 \mathrm{mg} / \mathrm{kg} /$ day at weekly intervals.

Patients with systemic disease other than epilepsy (liver, kidney, endocrine) and mental motor retardation, as well as children with a family history of atherosclerosis, were excluded from this study.

Blood samples drawn from patients after fasting for 12 hours at the beginning of treatment, and at $3^{\text {rd }}, 6^{\text {th }}$ and $12^{\text {th }}$ months were evaluated as for alanine aminotransferase (ALT), aspartate aminotransferase (AST), gamma-glutamyl transferase (GGT), total cholesterol (TC), triglyceride, low- density lipoprotein-cholesterol (LDL-K), high- density lipoprotein cholesterol (HDL-K), apolipoprotein A (Apo-A), apolipoprotein B (Apo-B), Lipoprotein a (Lp a), triiodothyrosine (T3), tetraiodothyrosine (T4), thyroid-stimulating hor- mone (TSH), hemogram, blood urea nitrogen, creatinine, sodium, potassium, calcium, phosphorus, glucose, vitamin B12, folic acid levels.

Serum ALT, AST, GGT of the patients were measured with the enzymatic colorimetric method, total cholesterol levels with cholesterol oxidase enzymatic method, triglyceride levels with glycerol oxidase enzymatic method. HDL-C was precipitated with phosphotungstic acid- $\mathrm{MgCl}$, and the supernatant portion was measured using a cholesterol oxidase method. Measurements were performed on Roche Modular autoanalyser. LDL-C levels were calculated using the Friedewald formula: [Total cholesterol- (Triglyceride $/ 5+\mathrm{HDL}-\mathrm{C})$ ]. Apo $A$ and $A$ po $B$ levels were measured by the immunonephelometric method using Behring nephelometer. $L p(a)$ levels were analyzed by antigen-antibody reaction using Tint Eliza kit and T3, T4, TSH levels were studied in autoanalyser by electrochemiluminescence immunoassay. Hemogram parameters were measured by LH 750 Bechan Coulter automatic hematometra. Sodium and potassium were analyzed using ion-selective electrode, calcium, and phosphorus with the calorimetric method, while glucose, blood urea nitrogen, creatinine with the enzymatic calorimetric method.

EEG and brain magnetic resonance imaging (MRI) were performed in all patients before treatment.

\section{Statistics Analysis}

SPSS 13.01 version was used for statistical analysis of the data obtained after the measurements. Friedman 2-way analysis of variance was used for the difference between repeated measures, and the significance level was accepted as $<0.05$. When significant differences were detected, the Wilcoxon test was used for post hoc comparison. An informed consent form was obtained from the families of all patients. Ethics Committee approval was obtained from the local Ethics Committee of the faculty (2003/18).

\section{Results}

Patients: The mean age of 10 female and five male patients included in this study was $8.47 \pm 3.09$ years. During a one-year follow-up, two patients whose seizures could not be controlled, and so started on additional antiepileptic drugs, and one patient who was not compliant with drug treatment were excluded from this study. The remaining 12 patients did not have seizures for one year. Ten patients (83.3\%) were diagnosed with complex partial epilepsy and two patients (16.7\%) with simple partial epilepsy. Considering the EEG findings of the patients, the focal epileptiform 
anomaly was detected in 10 and focal paroxysmal anomaly in two patients. MRI examination of the patients revealed cystic encephalomalacia in one and periventricular leukomalacia in another patient. Other patients had normal MRI results.

Common side effects of oxcarbazepine, such as rash, nausea, or headache, were not detected in any one of the patients.

Biochemical parameters: While ALT and AST values of oxcarbazepine-treated patients were not found to be different from baseline, a statistically insignificant increase was observed in GGT levels ( $p>0.05$ ) (Table 1).

When lipid parameters were examined, TC, LDL-C. HDL-C, Apo-A levels at the $3^{\text {rd }}, 6^{\text {th }}$ and $12^{\text {th }}$ months were not significantly different from baseline, whereas Apo B levels were significantly higher relative to baseline at 3 months $(p<0.05)$. Afterwards, ApoB values returned to baseline levels and decreased at the $12^{\text {th }}$ month (Table 1). There was a statistically significant increase in $\mathrm{Lp}$ (a) levels at $12^{\text {th }}$ month compared to baseline and 6th-month values $(p<0.05)$ (Table 1). Although there was an increase in the values at the $3^{\text {rd }}$ and $6^{\text {th }}$ months compared to baseline, the difference was not statistically significant ( $p>0.05$ ).

While free T4 levels of the patients decreased compared to baseline values, this decrease was not statistically significant. There was no change in other parameters of thyroid function tests in patients under oxcarbazepine treatment (Table 2).

Renal function test results, vitamin $\mathrm{B} 12$ and folic acid, $\mathrm{Na}$, $\mathrm{K}, \mathrm{Ca}, \mathrm{P}$ and ALP levels, white blood cell, hemoglobin and platelet counts measured at the $3^{\text {rd }}, 6^{\text {th }}$, and $12^{\text {th }}$ months were not significantly different from baseline values ( $p>0.05$ ) (Tables 2, 3).

\section{Discussion}

Most antiepileptic drugs make changes in metabolism, thyroid hormones, liver enzymes and lipid profile by in-

Table 1. The effects of oxcarbazepine on liver function tests, and lipids

\begin{tabular}{|c|c|c|c|c|}
\hline Parametres & \multicolumn{4}{|c|}{ Months, Median (min-max) } \\
\hline AST (U/L) & $27(9-35)$ & $26(10-30)$ & $24(16-35)$ & $26(17-33)$ \\
\hline GGT (U/L) & $12.5(9-20)$ & $18(10-30)$ & $17(10-49)$ & $18(11-40)$ \\
\hline $\mathrm{TC}(\mathrm{mg} / \mathrm{dl})$ & $163(120-234)$ & $166(135-204)$ & $177(68-296)$ & $173(137-230)$ \\
\hline LDL-C (mg/dl) & $97(56-152)$ & $95(48-159)$ & $107(67-188)$ & $111(65-145)$ \\
\hline $\mathrm{HDL}-\mathrm{C}(\mathrm{mg} / \mathrm{dl})$ & $51(38-83)$ & $56(29-122)$ & $59(46-73)$ & $54(5-87)$ \\
\hline Apo A (mg/dl) & $152(80-230)$ & $154(68-194)$ & $155(124-215)$ & $153(120-213)$ \\
\hline Apo B (mg/dl) & $78(7-116)^{a}$ & $88(40-125)^{b}$ & $79(11-103)$ & $69(9-104)$ \\
\hline $\mathrm{Lp}(\mathrm{a})(\mathrm{mg} / \mathrm{dL})$ & $7.3(2.8-23.8)^{c}$ & $9.3(3.6-24.4)$ & $8.9(3.8-25.3)^{d}$ & $13.6(4-55)^{e}$ \\
\hline
\end{tabular}

ALT: alanine aminotransferase; AST: aspartate aminotransferase; GGT: gamma-glutamyl transferase; TC: total cholesterol; LDL-C: low- density lipoprotein-cholesterol; HDL-C: high- density lipoprotein cholesterol; Apo A: apolipoprotein A; Apo B: apolipoprotein B; Lp a: Lipoprotein a. P<0.05 b-a; d-C; e-C.

Table 2. The effects of oxcarbazepine on thyroid functions, B12, and folic acid levels

\begin{tabular}{|c|c|c|c|c|}
\hline Parametres & \multicolumn{4}{|c|}{ Months, Median (min-max) } \\
\hline Folic acid (ng/ml) & $5.9(4.1-12)$ & $8.5(4.2-12.9)$ & $7.9(5-12.4)$ & $8(4-11)$ \\
\hline T3 (ng/mL) & $1.5(1.1-2.2)$ & $1.7(1.2-1.8)$ & $1.5(1.2-1.9)$ & $1.5(1.2-1.7)$ \\
\hline $\mathrm{T} 4$ (ug/dl) & $6.7(3.2-10)$ & $7.3(6-9.73)$ & $6.8(5.1-10)$ & $6.7(4.2-8.6)$ \\
\hline fT3 (pg/ml) & $3.7(2.5-4.8)$ & $3.9(3.6-4.5)$ & $3.7(3.3-4.5)$ & $4.06(1.21-4.6)$ \\
\hline fT4 (ng/dl) & $1.2(0.8-1.5)$ & $1.1(0.9-1.4)$ & $0.9(0.8-1.6)$ & $0.9(0.8-3.42)$ \\
\hline
\end{tabular}

T3: triiodothyrosine; T4: tetraiodothyrosine; TSH: thyroid-stimulating hormone. 
Table 3. The effects of oxcarbazepine on hemogram, renal function tests, and electrolytes

\begin{tabular}{|c|c|c|c|c|}
\hline \multirow[b]{2}{*}{ Parametres } & \multicolumn{4}{|c|}{ Months, Median (min-max) } \\
\hline & Baseline & 3 & 6 & 12 \\
\hline Hemoglobin (g/dL) & $12.1(11-13)$ & $12.2(11.7-12.9)$ & $12.1(11.3-14.4)$ & $12.2(11.7-12.9)$ \\
\hline \multirow[t]{2}{*}{ Platelets $(/ \mu \mathrm{L})$} & 320000 & 322000 & 292000 & 310500 \\
\hline & (195000-553000) & $(191000-515000)$ & $(191000-481000)$ & $(165000-551000)$ \\
\hline $\mathrm{K}(\mathrm{mEq} / \mathrm{L})$ & $4.3(3-4.5)$ & $4(4-5)$ & $4.4(3-5)$ & $4.2(3-4.5)$ \\
\hline $\mathrm{Ca}(\mathrm{mg} / \mathrm{dL})$ & $9.9(9.3-11)$ & $10(9.5-10.6)$ & $9.9(9.5-10.4)$ & $9.8(9.5-10.5)$ \\
\hline$P(\mathrm{mg} / \mathrm{dL})$ & $5(3.6-6.1)$ & $5.4(4-6)$ & $5.2(4.7-5.8)$ & $5.4(4.5-6.1)$ \\
\hline ALP (U/L) & $413(184-760)$ & $385(42-728)$ & $597(63-898)$ & $570(252-850)$ \\
\hline BUN (mg/dL) & $11(7-17)$ & $10.5(7-14)$ & $10(8-14)$ & $11(7-19)$ \\
\hline
\end{tabular}

Na: sodium; K: potassium; Ca: calcium; P: phosphorus; ALP: alkaline phosphatase; BUN: blood urea nitrogen.

ducing hepatic enzymes. In our study, clinical response, effects on liver enzymes, and lipid profiles were evaluated at three months intervals in children diagnosed with epilepsy while using oxcarbazepine. Based on the results obtained, a nonsignificant increase in GGT levels and a statistically significant increase in levels of $L p(a)$ that plays a role in the atherosclerotic process were detected.

There are many studies in the literature about the efficacy of oxcarbazepine. In a large meta-analysis, where oxcarbazepine was compared with other antiepileptic drugs (levetiracetam, phenytoin, valproic acid) and placebo, the findings showed that seizure rate, decrease in seizure frequency- i.e., drug efficacy- and drug side effects were similar to other antiepileptics, but more effective compared to placebo ${ }^{[5]}$. Again, in comparison with carbamazepine, oxcarbazepine was suggested to be more effective and more tolerable with lower side effects ${ }^{[3]}$.

Oxcarbazepine is an antiepileptic drug that can be used for monotherapy or as additional treatment in both focal and generalized seizures. In our study, 12 of $15(80 \%)$ patients had no recurrence of seizures during a one-year follow-up. When seizures of two patients persisted, a new antiepileptic treatment was added to the regimen. Rash-type eruptions, headache and gastrointestinal side effects that are common in the literature were not seen in our patients.

The effects of oxcarbazepine in inducing cytochrome P-450 enzyme compared to carbamazepine are minimal and known to be dose-dependent. In our study, although an increase in the level of a liver enzyme (i.e., GGT) occurred at $3^{\text {rd }}, 6^{\text {th }}$ and $12^{\text {th }}$ months compared to baseline, this elevation was not statistically significant. Significant changes in
ALT and AST values were not detected. The number of studies on the effects of oxcarbazepine on lipid profile is limited in the literature and the results are contradictory. In the study of Isojarvi et al. ${ }^{[8]}$, in the treatment of patients, carbamazepine was replaced with oxcarbazepine and decreased in TC and LDL-C levels of the patients were detected without any change in $\mathrm{HDL}-\mathrm{C}$ levels during the follow-up period. In contrast to the results of this study, increases in LDL-C levels were detected in children using oxcarbazepine ${ }^{[9,10]}$. In our study, Apo-B levels increased in the third month of treatment and returned to its normal levels at 12 months. Any change was not detected in total cholesterol, HDL-C, LDL-C, and triglyceride levels. Lp (a) level above $30 \mathrm{mg} / \mathrm{dl}$ is known to be a risk factor for atherosclerotic vascular disease ${ }^{[11,12]}$. In a study on the effects of oxcarbazepine on $\mathrm{Lp}$ (a), a significant increase in $\mathrm{Lp}$ (a) levels was found at the $8^{\text {th }}$ and $18^{\text {th }}$ months of treatment ${ }^{[11]}$. In a study from Turkey, Bozlu et al. ${ }^{[13]}$ found an increase in Lp (a) levels in patients using oxcarbazepine at the $3^{\text {rd }}$ month of treatment. The mechanism of elevation of $L p(a)$ levels with oxcarbazepine is not clear. However, there are several theories about this issue. One of them is an increase in Lp (a) levels, as a result of the increase of Apo B synthesis, the other theory is related to an increase in $L p$ (a) levels by induction of liver enzyme. The third theory involves a decrease in free thyroxine levels and the resulting subclinical hypothyroidism that may increase the $L p$ (a) level. In our study, increases in Lp (a) levels were detected at $3^{\text {rd }}, 6^{\text {th }}$ and $12^{\text {th }}$ months. It was thought that the decrease in free T4 level and dose-dependent reduction of cytochrome $\mathrm{P} 450$ - albeit mildly-induced by oxcarbazepine led to an increase in $L p(a)$ level. 
There are many studies in the literature about the effects of antiepileptic drugs on thyroid function tests. It has been detected that particularly, carbamazepine and oxcarbazepine induced a decrease in fT4 levels, but did not change TSH levels $[14,15]$, which has been attributed to increased metabolism of fT4 due to induction of liver enzymes. Again, the presence of normal TSH levels suggested that the hypothalamohypophyseal axis remained intact ${ }^{[14,15]}$. In our study, a nonsignificant decrease in fT4 levels was detected, which suggested that oxcarbazepine may accelerate the metabolism of thyroxine by induction of hepatic enzymes, albeit minimally, and that thyroid function tests should be monitored in patients using oxcarbazepine.

One of the undesirable effects of oxcarbazepine is hyponatremia. Many case reports in the literature have revealed hyponatremia related to oxcarbazepine use ${ }^{[16]}$. In a study comparing carbamazepine and oxcarbazepine concerning hyponatremia, it was reported that hyponatremia was seen at a higher rate (29\%) in patients using oxcarbazepine ${ }^{[17]}$. Cases with hyponatremia are usually asymptomatic. Both carbamazepine and oxcarbazepine have been suggested to cause hyponatremia by increasing ADH secretion or by increasing renal response to $\mathrm{ADH}{ }^{[17]}$. Although hyponatremia was not detected in our study, we think that patients receiving oxcarbazepine should be followed up for the presence of hyponatremia.

Oxcarbazepine, 10, 11-dihydro-10-hydroxy carbamazepine is glucuronidated in the liver and excreted in the urine, and also dose adjustment is recommended in renal failure ${ }^{[18]}$. Therefore, monitoring of renal functions in patients under oxcarbazepine treatment is recommended. In our study, deterioration in renal function tests was not observed in any of our patients.

In the literature, it was suggested that oxcarbazepine causes thrombocytopenia and thrombocytopenia that regress with the cessation of treatment, and these patients should be monitored concerning hemogram parameters $[19,20]$. Hyperhomocysteinemia is known to induce atherosclerosis through endothelial damage. Folic acid and vitamin B12 play a role in the conversion of homocysteine to methionine ${ }^{[21]}$. It is known that some antiepileptics decrease folic acid and vitamin B12 levels by increasing the metabolism of the liver via the induction of hepatic enzymes ${ }^{[22,23]}$. In their study, Gümüş et al. ${ }^{[21]}$ detected a decrease in folic acid but an increase in homocysteine levels during the follow-up of children diagnosed with epilepsy who were using oxcarbazepine, carbamazepine or valproate, without any change in vitamin B12 levels. In our study, leukopenia, thrombocytopenia, folic acid and decreases in vitamin B12 levels were not detected during oxcarbazepine use.

The limitation of our study was the small number of patients and we think that new studies should be performed with a higher number of cases to provide valuable insights. In conclusion, in our study, we thought that oxcarbazepine is an effective drug because of the seizure-free rate of $80 \%$ at the end of one year in patients taking oxcarbazepine. Because of the significant increase in $L p(a)$ levels, we think that lipids, mainly Lp (a) levels, and because of a decrease in free T4 level, thyroid function test results should be monitored.

Ethics Committee Approval: Ethics Committee approval was obtained from the local Ethics Committee of the faculty (2003/18). Peer-review: Externally peer-reviewed.

Authorship Contributions: Concept: I.G., F.M.S.; Design: I.G., F.M.S.; Data Collection or Processing: I.G., F.M.S., S.Y., A.Ö.; Analysis or Interpretation: S.Y., A.Ö.; Literature Search: I.G., F.M.S.; Writing: I.G., F.M.S.

Conflict of Interest: None declared.

Financial Disclosure: The authors declared that this study received no financial support.

\section{References}

1. Shneker BF, Fountain NB. Epilepsy. Dis Mon 2003;49:426-78.

2. Strolin Benedetti M, Ruty B, Baltes E. Induction of endogenous pathways by antiepileptics and clinical implications. Fundam Clin Pharmacol 2005;19:511-29. [CrossRef]

3. Schmidt D, Elger CE. What is the evidence that oxcarbazepine and carbamazepine are distinctly different antiepileptic drugs? Epilepsy Behav 2004;5:627-35. [CrossRef]

4. Rambeck B, Specht U, Wolf P. Pharmacokinetic interactions of the new antiepileptic drugs. Clin Pharmacokinet 1996;31:30924. [CrossRef]

5. Geng H, Wang C. Efficacy and safety of oxcarbazepine in the treatment of children with epilepsy: a meta-analysis of randomized controlled trials. Neuropsychiatr Dis Treat 2017;13:685-95.

6. Beydoun A. Safety and efficacy of oxcarbazepine: results of randomized. double-blind trials. $\mathrm{P}$ Pharmacotherapy 2000;20:152S-8S. [CrossRef]

7. Engel J Jr; International League Against Epilepsy (ILAE). A proposed diagnostic scheme for people with epileptic seizures and with epilepsy: report of the ILAE Task Force on Classification and Terminology. Epilepsia 2001;42:796-803. [CrossRef]

8. Isojärvi Jl, Pakarinen AJ, Rautio A, Pelkonen O, Myllylä VV. Liver enzyme induction and serum lipid levels after replacement of carbamazepine with oxcarbazepine. Epilepsia 1994;35:121720. [CrossRef]

9. Serdaroglu G, Kurul S, Tutuncuoglu S, Dirik E, Sarioglu B. Oxcarbazepine in the treatment of childhood epilepsy. Pedi Pediatr Neurol 2003;28:37-41. [CrossRef] 
10. Papacostas $S$. Oxcarbazepine versus carbamazepine treatment and induction of serum lipid abnormalities. J Child Neurol 2000;15:138-40. [CrossRef]

11. Garoufi A, Koemtzidou E, Katsarou E, Dinopoulos A, Kalimeraki I, Fotinou $A$, et al. Lipid profile and thyroid hormone concentrations in children with epilepsy treated with oxcarbazepine monotherapy: a prospective long-term study. Eur J Neurol 2014;21:118-23. [CrossRef]

12. Bostom AG, Cupples LA, Jenner JL, Ordovas JM, Seman LJ, Wilson PW, et al. Elevated plasma lipoprotein (a) and coronary heart disease in men aged 55 years and younger. A prospective study. JAMA 1996;276:544-8. [CrossRef]

13. Bozlu G, Okuyaz C, Eskandari G, Mert E. ETP027 Effects of oxcarbazepine on serum lipid, lipoprotein (a), homocysteine, folate and vitamin B12 levels in children with partial epilepsy. European Journal of Paediatric Neurology 2007;11:121. [CrossRef]

14. Cansu A, Serdaroğlu A, Camurdan O, Hirfanoğlu T, Bideci A, Gücüyener K. The evaluation of thyroid functions, thyroid antibodies, and thyroid volumes in children with epilepsy during short-term administration of oxcarbazepine and valproate. Epilepsia 2006;47:1855-9. [CrossRef]

15. Verrotti A, Basciani F, Morresi S, Morgese G, Chiarelli F. Thyroid hormones in epileptic children receiving carbamazepine and valproic acid. Pediatr Neurol 2001;25:43-6. [CrossRef]

16. Değirmenci Y, Yılmaz Y, Hayretdağ Ö, Özışık Karaman H. Okskarbazepin Kullanımına Bağlı Ağır Hiponatremi Olgusu. Epilepsi
Derg 2011;17:58-60. [CrossRef]

17. Polat F, Güllüoğlu $H$, Araç N. Karbamazepin ve okskarbazepin tedavisi ile ilişkili hiponatremi. Epilepsi 2010;16:107-12.

18. Schütz H, Feldmann KF, Faigle JW, Kriemler HP, Winkler T. The metabolism of oxcarbazepine in man. Xenobiotica 1986;16:769-78. [CrossRef]

19. Mahmud J, Mathews M, Verma S, Basil B. Oxcarbazepine-induced thrombocytopenia. Psychosomatics. 2006;47:73-4.

20. Tutor-Crespo MJ, Hermida J, Tutor JC. Relation of blood platelet count during carbamazepine and oxcarbazepine treatment with daily dose, and serum concentrations of carbamazepine, carbamazepine-10, 11-epoxide, and 10-hydroxycarbazepine. Biomed Pap Med Fac Univ Palacky Olomouc Czech Repub 2007;151:91-4. [CrossRef]

21. Gümüş H, Kumandaş S. ETP028 Effects of common anti-epileptic drugs and oxcarbazepine monotherapy on serum levels of homocysteine, vitamin B12, folic acid. Eur J Paediatr Neurol 11.p.121. [CrossRef]

22. Karabiber H, Sonmezgoz E, Ozerol E, Yakinci C, Otlu B, Yologlu $\mathrm{S}$. Effects of valproate and carbamazepine on serum levels of homocysteine, vitamin B12, and folic acid. B Brain Dev 2003;25:113-5. [CrossRef]

23. Krause KH, Bonjour JP, Berlit P, Kynast G, Schmidt-Gayk H, Schellenberg B. Effect of long-term treatment with antiepileptic drugs on the vitamin status. Drug Nutr Interact 1988;5:317-43. 